Supporting Information for

\title{
Injectable Biocatalytic Nanocomposite Hydrogel Factories for Focal Enzyme-Prodrug Cancer Therapy
}

Kimika Ono, Hiroyuki Hashimoto, Tokitaka Katayama, Natsumi Ueda, and Koji Nagahama*

Department of Nanobiochemistry, Frontiers of Innovative Research in Science and Technology (FIRST), Konan University, 7-1-20 Minatojima-Minamimachi, Chuo-ku, Kobe 650-0047, Japan 

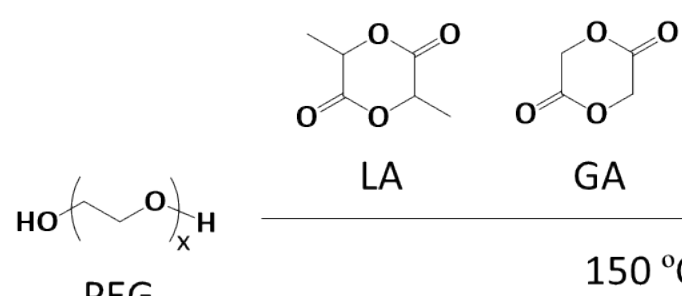

LA

GA

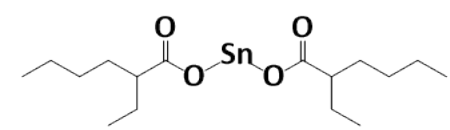

PEG

$$
150^{\circ} \mathrm{C}, 6 \mathrm{~h}
$$

\section{$\mathrm{Sn}(\mathrm{Oct})_{2}$}

( $\left.M_{\mathrm{w}}: 1.5 \mathrm{k}, 3 \mathrm{k}\right)$

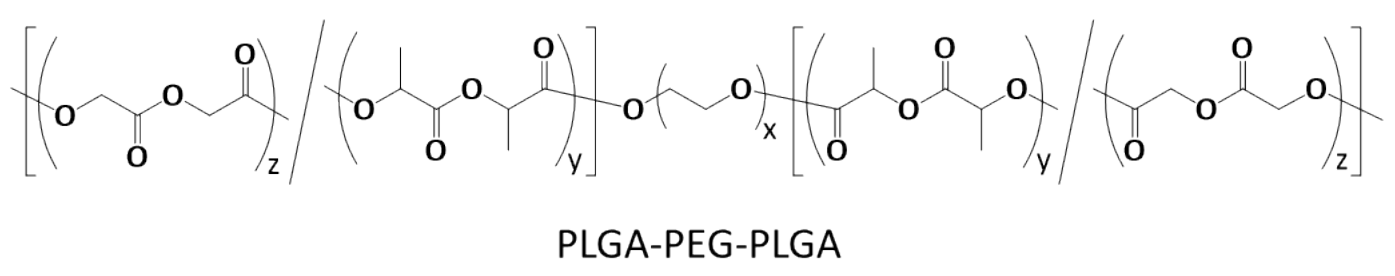

Scheme S1. Synthesis of PLGA-PEG-PLGA copolymers. 


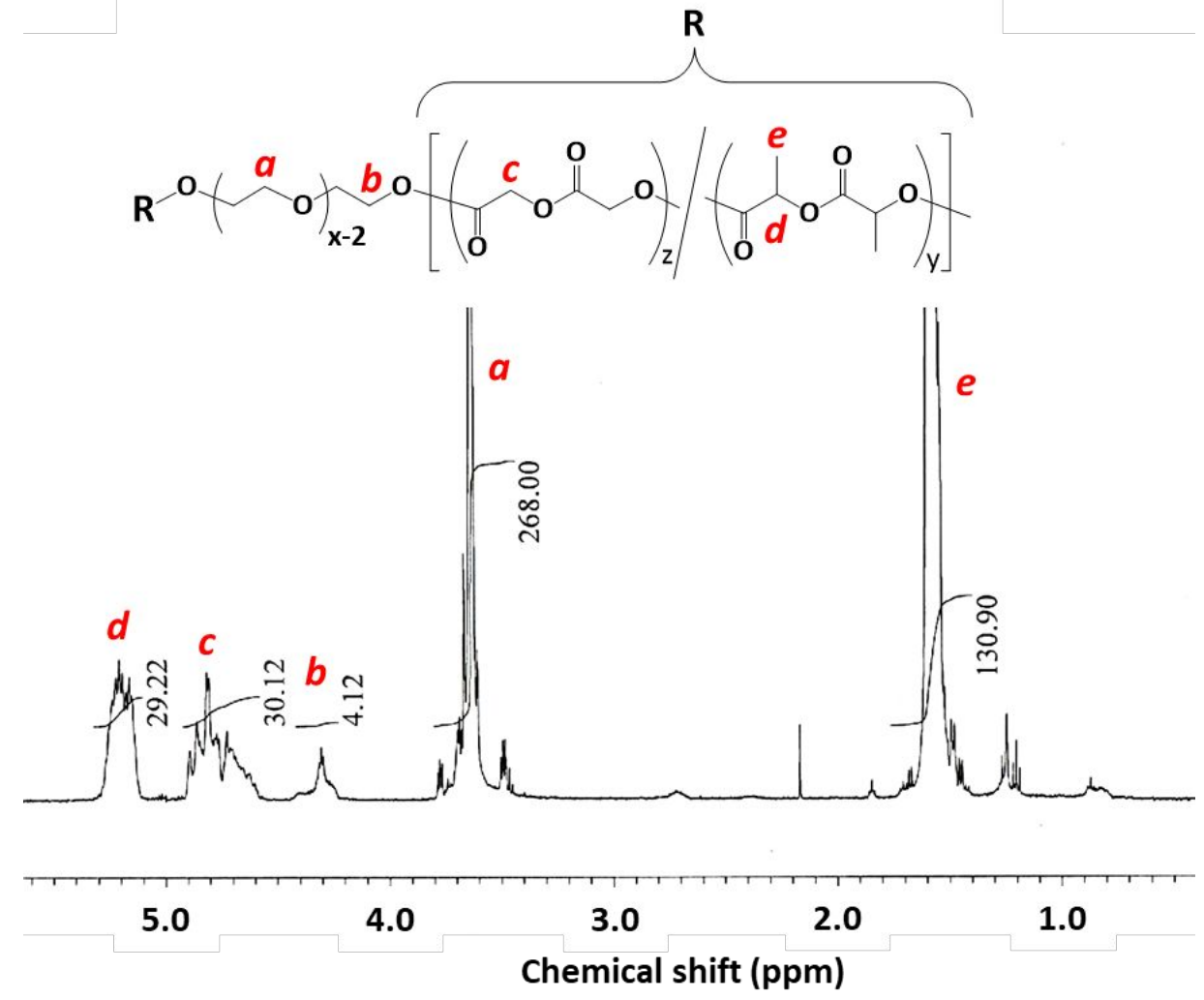

Figure S1. ${ }^{1} \mathrm{H}-\mathrm{NMR}$ spectrum of the synthesized PLGA-PEG-PLGA copolymer $\left(\mathrm{P}_{3 \mathrm{k}}\right)$. 
Table S1. Characterization of PLGA-PEG-PLGA copolymers used in this study.

\begin{tabular}{|c|c|c|c|c|c|}
\hline copolymer & DP of LA & DP of GA $^{a}$ & $M_{\mathrm{w}}$ of PEG & $M_{\mathrm{w}}$ of copolymer & $M_{\mathrm{w}} / M_{\mathrm{n}}^{c}$ \\
\hline PLGA-PEG $_{1.5 \mathrm{k}}-\mathrm{PLGA}\left(\mathrm{P}_{1.5 \mathrm{k}}\right)$ & 8 & 4 & 1,500 & 4,800 & 1.18 \\
\hline PLGA-PEG $_{3 \mathrm{k}}$-PLGA $\left(\mathrm{P}_{3 \mathrm{k}}\right)$ & 8 & 4 & 3,000 & 6,300 & 1.15 \\
\hline
\end{tabular}

${ }^{a}$ Estimated by ${ }^{1}$ H-NMR. ${ }^{b}$ Estimated by following equation; $M_{\mathrm{w}}$ of copolymer $=M_{\mathrm{w}}$ of PEG segment $+2 \times\left(M_{\mathrm{w}}\right.$ of PLGA segment). ${ }^{c}$ Estimated by GPC (eluent: DMSO, standard: PEG). 